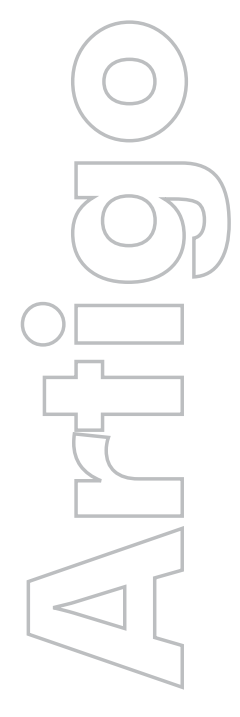

\title{
Pobreza estrutural globalizada, território brasileiro e política de transferência de renda: o Programa Bolsa Família como evento
}

Fernando Antonio Silva

Unicamp

p. $48-72$

revista

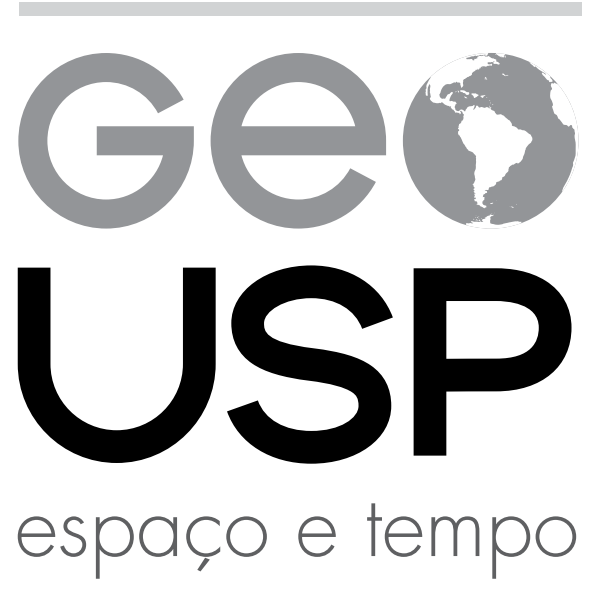

Volume $21 \bullet \mathrm{n}^{\circ} 1(2017)$

ISSN 2179-0892
Como citar este artigo:

SILVA, F. A. Pobreza estrutural globalizada, território brasileiro e política de transferência de renda: o Programa Bolsa Familia como evento. Geousp - Espaço e Tempo (Online), v. 21, n. 1, p. 48-72, abril. 2017. ISSN 2179-0892.

Disponível em:

$<$ http://www.revistas.usp.br/geousp/article/view/111813 $>$. doi: 10.11606/issn.2179-0892.geousp.2017.111813.

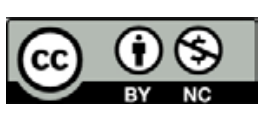

Este artigo está licenciado sob a Creative Commons Attribution 4.0 License. 


\section{Pobreza estrutural globalizada, território brasileiro e política de transferência de renda: o Programa Bolsa Família como evento}

\section{Resumo}

No Brasil, os programas de transferência de renda passou de um debate de cunho sobretudo teórico, na década de 1970, para questões relativas à implantação ou avaliação de experiências concretas nos anos 1990, chegando o país a ter uma das principais experiências do mundo nesse tipo de política: o Programa Bolsa Família (PBF) (Brasil, 2003). Esse processo indica profundas mudanças nas formas político-institucionais de conceber e agir sobre a pobreza, que, portanto, deve ser compreendida a partir da dinâmica de cada período. Vista no seu funcionamento, a política do Bolsa Família renova a dinâmica do território, tornando mais complexa a apreensão das formas de reprodução da pobreza nos lugares. Propomos tratar essa política por meio da teoria geográfica como um evento. Procuramos identificar, de um lado, os principais condicionantes que moldaram a política brasileira de transferência de renda e, de outro, novas dimensões da reprodução da pobreza em lugares onde o evento se concretiza a partir de situações do interior do estado de Alagoas.

Palavras-chave: Política de transferência de renda. Bolsa Família. Pobreza. Território. Circuitos da economia urbana.

\section{Structural globalized poverty, brazilian territory and cash transfer policy: the Bolsa Família Program as an event}

\footnotetext{
Abstract

In Brazil, the subject of cash transfer programs went from a mainly theoretical debate, at the 1970s, to the predominance of issues related to the implantation or evaluation of concrete experiences at the 1990s, so that the country
} 
had one of the top experiences in the world with this type of policy: the Bolsa Familia Program (Brasil, 2003). This process indicates deep changes in the political and institutional ways of conceiving and acting on poverty; therefore, it should be understood from each period's own dynamics. Seen in operation, the Bolsa Familia policy renews the dynamics of the Brazilian territory, making it more complex to grasp the forms of poverty reproduction in places. We propose to address this policy, through geographic theory, as an event. We seek to identify, on the one hand, the main conditioning factors that shaped the Brazilian cash transfer policy and, on the other hand, new dimensions of poverty reproduction in the places where the event is concretized, from situations at inland towns in the state of Alagoas, Brazil.

Keywords: Cash transfer policy. Bolsa Família. Poverty. Territory. Circuits of the urban economy.

\section{Introdução}

Claramente temos observado que o processo de globalização com o qual nosso país vem se defrontando, notadamente desde a década de 1990, tem implicado reconfigurações expressivas e complexas nos setores e instituições que compõem o Estado e, de forma mais ampla, neste em face da dinâmica do território. Esse processo envolve, antes de mais nada, a redefinição das concepções que informam as ações estatais, isto é, que fundamentam as políticas públicas. Exemplar nesse sentido é a inserção na agenda do Estado brasileiro de novas políticas vinculadas diretamente à temática da pobreza, como são os programas de transferência de renda e as concepções de pobreza que thes servem como justificação.

A temática das políticas de transferência de renda está na própria origem do capitalismo industrial (Polanyi, 1980). Foi retomada nos países do centro do sistema capitalista durante o século XX em dois momentos: primeiro durante a expansão do Estado de bem-estar social, quando alguns programas dessa natureza foram implantados em países como Dinamarca, Reino Unido e Alemanha; segundo, com a crise do capitalismo da década de 1970 em função da desestabilização das relações de trabalho que mantinham o Estado de bemestar, sendo emblemático desse momento o Renda Mínima de Inserção (RMI) francês. No Brasil, porém, essa discussão só foi iniciada em 1975 quando Antonio Maria da Silveira publicou, na Revista Brasileira de Economia, o texto intitulado "Redistribuição de renda". A implantação de políticas de transferência de renda em nosso território, contudo, é mais recente. As primeiras experiências surgiram somente em 1995 no município de Campinas e no Distrito Federal. Queremos 
sugerir que, diferente do que aconteceu nos países do centro do sistema capitalista, essa mudança de perspectiva em relação à política de transferência, que levou à sua aceitação e aplicação no Brasil de 1990, insere-se em formas político-institucionais de conceber e agir sobre a pobreza características do período atual.

Para Santos (2011, p. 56), nos dias de hoje vive-se uma pobreza que "[...] resulta da convergência de causas que se dão em diversos níveis, existindo como vasos comunicantes". Por isso, merece o nome de pobreza estrutural globalizada. Na realidade, trata-se da forma concreta de manifestação da pobreza no período da globalização que se sustenta por meio de uma nova construção discursiva e se reproduz segundo as singularidades históricas de cada país. Buscamos situar nesse contexto de pobreza a convergência entre território brasileiro e políticas de transferência de renda.

Todavia, assumiremos que o Programa Bolsa Família (PBF), implantando no início do governo Lula (2003) e sendo hoje uma das principais experiências de programas de transferência de renda no mundo, revela rupturas e continuidades em relação aos programas da década de 1990. Ao ampliar e estender a política para grandes parcelas da população brasileira, o que resulta em transformações significativas na dinâmica dos lugares mais pobres do país, mas herdar e consolidar elementos fundamentais que acomodaram essa política e os demais mecanismos propulsores da globalização no território brasileiro, o PBF acaba por contribuir contraditoriamente para a institucionalização da pobreza estrutural globalizada.

Para compreendermos o PBF, iremos argumentar que esta política pode ser analisada como um evento planejado (Santos, 2009a), cuja duração depende de um sistema de instituições, normas, objetos e ações. Sua origem e funcionamento revelam, por uma parte, os condicionamentos que moldaram a política de transferência de renda brasileira e, por outra, a complexidade sobre a qual assenta-se a reprodução da pobreza no período atual.

Além desta introdução, o artigo está organizado em mais quatro partes. Primeiro apresentamos uma proposta de periodização para as políticas de transferência de renda no território brasileiro. Segundo, defendemos a possibilidade de compreender o PBF como um evento. Na terceira parte apontamos alguns caminhos para discutir o PBF na sua escala de realização, usando para isso a teoria dos dois circuitos da economia urbana (Santos, 2008) a partir de algumas situações do interior do estado de Alagoas. Na quarta parte estão as considerações finais que sintetizam os argumentos do artigo.

\section{Território brasileiro e política de transferência de renda}

Segundo Jacques Le Goff (2015, p. 11-12), a palavra "período" vem do grego períodos, que significa um caminho circular. Foi em algum momento entre os séculos XIV e XVIII que o termo ganhou o sentido de intervalo de tempo ou 
idade. A palavra periodização, porém, surgiu somente no século $\mathrm{XX}$ e, como recurso de método especial do historiador para recortar o tempo em pedaços coerentes, conferindo sentido à história, "[...] indica uma ação humana sobre o tempo e sublinha que seu recorte não é neutro" (Le Goff, 2015, p. 12, grifos nossos).

Ao dizer que a geografia pode ser definida como o estudo do espaço humanizado, Pierre George (1968) lembra que especialmente durante o século $\mathrm{XX}$ a ação do homem se direcionou à arrumação do espaço, ficando esta arrumação como uma espécie de herança para as gerações futuras. Assim, se a preocupação "consiste em partir, não da sociedade para atingir o espaço, mas do espaço para atingir a sociedade" (Isnard, 1982, p. 40), um pressuposto básico é o de que "[...] espace et société n'évoluent pas au même rythme" (Isnard, 1985, p. 543).

Para Santos (2004, p. 22), a história do espaço é explicada pelo tempo social que "[...] leva à noção de periodização da história e essa necessidade epistemológica provém do fato de que a História é, a um só tempo, contínua e descontínua". Santos (2009b) propõe mais tarde que o espaço seja compreendido como "acumulações desiguais de tempo". Na versão mais elaborada de sua teoria espacial, Santos (2009a) afirma que a geografia pode fornecer elementos importantes para a compreensão da história e dos períodos tornando o tempo empírico, valendo-se para isso das noções de evento e de meio, a primeira oriunda da filosofia e a segunda proposta originalmente pelo geógrafo Maximilien Sorre.

Partiremos do suposto de que a história do território brasileiro pode ser dividida em períodos, e de que uma análise acurada de seu período mais recente revela certa convergência com a história das políticas de transferência de renda. Para isso, admitimos que o evento constitui uma fatia concreta de espaço-tempo (Bachelard, 1994), e que um período, como sinônimo de duração, pode ser definido pela simultaneidade de um conjunto de acontecimentos. "Uma duração é uma fatia concreta da natureza limitada pela simultaneidade, fator essencial revelado na apreensão sensível" (Whitehead, 1994, p. 66, grifos nossos).

Entre as pesquisas sobre as políticas de transferência de renda no Brasil, certa atenção é de dicada ao processo de formação da política, às convergências de interesses que se materializam em cada programa, bem como às especificidades que esse tipo de política adquiriu no Brasil (Silva, M., 1997; Fonseca, 2001; Suplicy, 2013; Cotta, 2009; Tomazini, 2010). Não obstante, diríamos que são menos comuns os esforços que, a partir do arcabouço teórico-metodológico de uma disciplina, busque continuidades e rupturas na trajetória desses programas. É este o esforço que buscamos fazer. Nossa proposta de periodização, resumida no Quadro 1, é baseada em formas e visões da pobreza originadas nas modernizações incompletas do território brasileiro (Quijano, 1998; Santos, 2011; Silveira, M., 2005). 


\section{Quadro 1}

\section{Proposta de periodização para as políticas de transferência de renda no Brasil}

\begin{tabular}{|c|c|c|}
\hline período & característica & eventos \\
\hline $\begin{array}{l}\text { lo período: pobreza marginal } \\
(1975-1990)\end{array}$ & $\begin{array}{l}\text { propostas dispersas e de } \\
\text { cunho mais teórico para } \\
\text { políticas de transferência } \\
\text { de renda }\end{array}$ & $\begin{array}{l}\text { primeira proposta de } \\
\text { transferência de renda, de } \\
\text { Antonio Maria da Silveira } \\
\text { (1975); segunda proposta } \\
\text { de Bacha e Unger (1978) }\end{array}$ \\
\hline $\begin{array}{l}2 \circ \text { período: pobreza } \\
\text { estrutural globalizada (1991- } \\
\text { até hoje) }\end{array}$ & $\begin{array}{l}\text { aceitação, aplicação e } \\
\text { estruturação das políticas } \\
\text { de transferência de renda }\end{array}$ & $\begin{array}{l}\text { dois marcos importante } \\
\text { são: a apresentação do } \\
\text { Projeto de Lei para um } \\
\text { Programa de Garantia } \\
\text { de Renda Mínima pelo } \\
\text { senador Eduardo Suplicy } \\
\text { (Brasil, 1991) e a criação } \\
\text { do Programa Bolsa Família } \\
\text { (Brasil, 2003) }\end{array}$ \\
\hline $\begin{array}{l}\text { subperíodo } 1 \\
(1991-2002)\end{array}$ & $\begin{array}{l}\text { incorporação/ } \\
\text { amoldamento da política } \\
\text { de transferência de renda } \\
\text { à formação socioespacial } \\
\text { brasileira }\end{array}$ & $\begin{array}{l}\text { Projeto de Lei de Eduardo } \\
\text { Suplicy (Brasil, 1991); } \\
\text { implantação de programas } \\
\text { em Campinas e no } \\
\text { Distrito Federal (1995); } \\
\text { Implantação de programas } \\
\text { de transferências nacionais } \\
\text { ligados à educação (1997 e } \\
\text { 1999) e saúde (2001) }\end{array}$ \\
\hline $\begin{array}{l}\text { subperíodo } \\
2 \text { ( } 2003 \text { até } \\
\text { hoje) }\end{array}$ & $\begin{array}{l}\text { consolidação das políticas } \\
\text { de transferência de renda } \\
\text { entre políticas sociais } \\
\text { brasileiras }\end{array}$ & $\begin{array}{l}\text { criação do Programa Bolsa } \\
\text { Família (Brasil, 2003) }\end{array}$ \\
\hline
\end{tabular}

organização: Fernando Silva (2016).

De acordo com Quijano (1998), durante os chamados "30 gloriosos" (19451975), mesmo entre os agentes que defendiam a entrada dos países latino-americanos na modernização tecnológica havia uma crença de que as benesses do crescimento econômico alcançariam, cedo ou tarde, as populações mais pobres, ou seja, havia uma preocupação moral com o destino dos pobres. Mesmo que essa expectativa não se concretize, as ações do Estado e de certos agentes privados são informadas por essa preocupação. É o que Santos (2011) chama de pobreza marginal. Ao tratar da especificidade do Brasil nesse aspecto, M. Silveira (2005) explica que a industrialização seletiva do país provocou grandes fluxos migratórios para o Sudeste, e à medida que o desemprego aumentava pela incapacidade de absorção dessa mão de obra nas grandes indústrias, a pobreza passou a ser alvo de ações inspiradas nos Estados de bem-estar social. Compreendemos que, de certo modo, essa forma de pobreza no Brasil continua até quando o modelo econômico adotado começa a dar sinais de esgotamento com a crise 
da dívida externa da década de 1980. Sprandel (2004) nos mostra que a preocupação brasileira com a pobreza como estigma a ser superado ainda domina boa parte da década de 1980, incorporando, notadamente nesta década, a crença de que tal superação viria por vias democráticas.

Portanto, de 1975 a 1990, as propostas para políticas de transferência de renda no Brasil situam-se no período da pobreza marginal. Podemos afirmar que foi em 1975, com a publicação do texto "Redistribuição de renda", de Antonio Maria da Silveira (1975), na Revista Brasileira de Economia, que o debate brasileiro sobre essas políticas foi inaugurado. Não estamos querendo dizer, portanto, que esse texto de Antonio Maria da Silveira inaugura o período da pobreza marginal, mas tão somente que a incorporação e o lugar que o tema das políticas de transferência vão ter inicialmente no nosso país se explicam pelas variáveis desse período.

Vale lembrar que Antonio Maria da Silveira (1975) propôs uma política de transferência na forma de um Imposto de Renda Negativo, ideia cujo principal defensor no mundo foi o economista liberal Milton Friedman. Silveira teve contato nos EUA com a proposta de Friedman anos antes de defender a ideia no Brasil. Como mostra detalhadamente Stein (2005), as políticas de transferência de renda que foram implantadas no início do século XX em vários países europeus como Reino Unido, em 1948, Finlândia, em 1956, Alemanha, em 1961, e Holanda, em 1963, no âmbito da expansão dos Estados de bem-estar social, promoveram e ao mesmo tempo se alimentam de profundos e longos debates em torno do tema. Entretanto, assinala Fonseca (2001), esses debates não se verificaram no Brasil, aqui o tema já foi incorporado a partir da perspectiva liberal de Milton Friedman.

Definitivamente, o modelo de crescimento econômico que originou a pobreza marginal impunha sérios constrangimentos à difusão das políticas de transferência de renda nos países da periferia capitalista. Por um lado, as propostas mais conservadoras para esse tipo de política alinhavam-se explicitamente ao livre mercado e às críticas que essas propostas recebiam estampavam que o objetivo das transferências seria apenas amenizar os efeitos perversos da modernização; por outro lado, as propostas mais progressistas que informaram muitos debates e políticas na Europa nem sequer foram ponderadas no Brasil. Conforme mostra o Quadro 1, além da proposta de Silveira, só tivemos a de Bacha e Unger (1978).

Todavia, o território brasileiro conhece mudanças profundas durante as décadas de 1980-90, mudanças que têm a ver com a opção política pelo ingresso na globalização econômica. C. Silva (2012, p. 98) faz a interessante proposição de compreendermos a nova camada de modernização que alcança o Brasil no início dos anos 1990 como resultado da disputa de narrativas no âmbito da leitura da crise da dívida externa de 1980, ou seja, "a crise possui, portanto, duas dimensões: uma real-concreta, vinculada à desintegração das instituições sociais, e a segunda, referente à dimensão discursiva da crise [...]". Por isso, a pressão do Fundo Monetário Internacional (FMI) para que o país seguisse as orientações do Consenso de Washington (1989) foram, na realidade, imposições de novas concepções de desenvolvimento e de políticas, que se direcionaram 
especialmente aos setores do Estado. O projeto/discurso vitorioso materializou-se nas reformas neoliberais dos governos Fernando Collor, Itamar Franco e Fernando Henrique Cardoso. Fazem parte da nova camada modernizadora renovação/privatização dos equipamentos de circulação do território (rodovias, hidrovias, portos etc.) e de empresas estatais, abertura à mundialização financeira, transformações nas legislações trabalhistas etc. Acontece, então, como aponta M. Silveira (2005, p. 170):

Nesse território adaptado a uma produção e uma circulação modernas, o crescimento não beneficia a sociedade e o território como um todo. Parcelas crescentes da população são excluídas na formulação desses projetos e, por isso, estamos diante de uma 'pobreza estrutural'. É, no dizer de Milton Santos, uma produção científica, globalizada e voluntária da pobreza.

Conforme Ugá (2004, p. 61), o Banco Mundial tem, desde 1990, reformulado suas estratégias e recomendado aos países em desenvolvimento ações para o enfrentamento dos elevados custos sociais decorrentes das políticas neoliberais e "[...] a novidade introduzida [...] foi que a categoria "pobreza" passou a ser uma peça-chave de uma ordem social implícita nos relatórios do Banco Mundial e hegemônica na formulação de políticas nos nossos países". A autora defende que existe nesse processo a construção de uma teoria tácita sobre a pobreza, pensada agora como estigma do próprio indivíduo que não tem renda suficiente (definida por uma linha de pobreza) e/ou capital humano (principalmente acesso à educação) para superar sozinho essa situação. Daí a necessidade de o Estado construir mecanismos eficientes para focalizar suas ações contra pobreza nessas populações. Telles (2001, p. 10), ponderando sobre as políticas neoliberais do início dos anos 1990, resume bem os contornos desse novo período: a pobreza passou de indicativo de atraso a ser superado para a condição de "cifra de nossa própria modernidade, que apenas acompanha as tendências consideradas inelutáveis no mundo inteiro em tempos de globalização e aceleração tecnológica". Essa pobreza merece ser chamada de estrutural globalizada porque, embora se manifeste nos lugares, "resulta da convergência de causas que se dão em diversos níveis, existindo como vasos comunicantes e como algo racional, um fenômeno inevitável, considerado até mesmo um fato natural" (Santos, 2011, p. 56).

É nesse contexto que, no Brasil, apesar de divergências sobre questões relativas ao desenho dos programas, às formas de financiamento etc., instaura-se certo consenso sobre a validade das políticas de transferência de renda como medidas contra a pobreza (Cotta, 2009; Tomazini, 2010). Por isso, pode-se dizer que o período da pobreza estrutural globalizada, o segundo na nossa periodização, é caracterizado pela aceitação e aplicação das políticas de transferência de renda. Um marco importante é o ano de 1991 quando o senador Eduardo Suplicy apresentou Projeto de Lei para um Programa de Garantia de Renda Mínima (Brasil, 1991), também na forma de Imposto de Renda Negativo. O Projeto teve grande aceitação, evidentemente não foi levado a efeito em função da situação políticoeconômica do país. Daí em diante, a formação socioespacial brasileira vai moldando, a 
partir de constrangimentos impostos por organismos e organizações internacionais (Stein, 2005; Cohn, 2012), mas também de condicionamentos internos, sua própria política de transferência de renda. ${ }^{1}$

Nesse sentido, destacam-se os seguintes acontecimentos: proposta feita por José Márcio de Camargo $(1993)^{2}$ de vinculação das transferências à exigência de frequência escolar; implantação dos primeiros programas em Campinas-SP e no Distrito Federal, em 1995, e dos programas Para Toda Criança na Escola, em 1997, e Bolsa Escola, em 2001, ambos do governo Fernando Henrique Cardoso; implantação de um programa de transferência vinculado à saúde, o Bolsa Alimentação, em 2001; apresentação pelo senador Eduardo Suplicy de um Projeto de Lei de renda básica (Brasil, 2001b). Para M. Silva et al. (2006), a novidade da política brasileira de transferência de renda, construída ao longo da década de 1990, está nas chamadas condicionalidades, isto é, na vinculação das transferências à frequência escolar e acompanhamento médico. De certo modo, essa novidade, que se espalha por vários países da América Latina, continua ainda mais forte com o Programa Bolsa Família (Brasil, 2003).

Todavia, assumiremos que a criação do PBF insere-se em um novo subperíodo da pobreza estrutural globalizada na formação socioespacial brasileira, o que se revela a partir de novas relações das políticas de transferência de renda com o território em função das seguintes novidades que o PBF traz: (a) ampliação das transferências para todas as famílias a partir de determinada faixa de renda, mesmo para aquelas que não têm em sua composição crianças e adolescentes em idade escolar; (b) ampliação significativa dos valores transferidos para os beneficiários; (c) estruturação legal-institucional da política, com a criação do Ministério do Desenvolvimento Social e Combate à Fome (MDS) e as articulações federativas para durabilidade da política. Acirram-se as contradições porque, no limite, o PBF caminha na direção de consolidar as políticas de transferência de renda entre as chamadas políticas de combate à pobreza no Brasil.

1 Não se pode esquecer o papel da Organização das Nações Unidas (ONU) na realização das Conferências Mundiais na década de 1990. Destaca-se a Conferência Mundial de Copenhague, em 1995, intitulada "Desenvolvimento Social", quando 117 chefes de Estado e de governo, entre eles o Brasil, assumiram o compromisso de erradicar a "pobreza" no mundo. Esse compromisso foi ratificado nos objetivos de desenvolvimento do milênio (ODM) assumidos em Nova York, em 2000. No Brasil, destacam-se: a Ação da Cidadania, de 1993, movimento liderado pelo sociólogo Herbert de Souza (Betinho) que buscava "sensibilizar" a população para lutar contra a "pobreza"; a Proposta de Emenda Constitucional (PEC) n. 67 (Brasil, 1999a), de autoria do senador Antonio Carlos Magalhães (PFL-BA) de criar um Fundo de Combate à Pobreza, que resultou na criação de uma Comissão Mista Especial da Câmara e do Senado para estudar as causas da pobreza; e o Projeto de Lei n. 66 (Brasil, 1999b) de autoria do senador Eduardo Suplicy que propunha instituir uma linha oficial de pobreza. Essas ações, apesar de orientadas por diferentes perspectivas políticas, concorreram para criar consenso sobre as políticas de transferências de renda.

2 Como relata Suplicy (2013), a proposta de José Márcio de Camargo foi apresentada numa reunião do Partido dos Trabalhadores (PT) em 1991 e propunha condicionar as transferências à frequência escolar. Entretanto, só em 1993, no texto "Os miseráveis", que Camargo defendeu mais sistematicamente seus argumentos. Seu argumento central era o de que os filhos da população pobre não conseguiam estudar porque precisavam trabalhar cedo, ocupando assim as piores profissões no mercado de trabalho. Se uma política conseguisse garantir o dinheiro que as crianças e os adolescentes ganhavam mantendo-os na escola, o ciclo da "reprodução intergeracional" da pobreza seria rompido. 


\section{O Programa Bolsa Família como evento}

As primeiras aproximações com a ideia de evento aparecem nas definições aristotélicas para ação e atualidade, a primeira tomada como resultado de uma escolha deliberada - o que já exclui as leis do universo, pois estas já estão dadas -, e a segunda referida à capacidade que algo tem mudar, de atualizar-se. Movimento, possibilidade, atualidade e mudança são quatro termos que guardam, desde Aristóteles, certa sinonímia com ação. Desde então, a preocupação com as ideias de tempo e movimento, como mostra a obra organizada por Schnell (2007), esteve presente entre vários filósofos (Plotino, Augustinho, Leibniz, Kant, Schelling, Bergson, Husserl, entre outros), mas nem sempre de maneira sistemática nem muito menos sob o prisma da categoria evento. Esta vai ganhar destaque principalmente nas filosofias de pensadores do século XIX e XX como: Alfred Whitehead, Martin Heidegger, Gaston Bachelard, Bertrand Russel, Henry Lefebvre, Norbert Elias, entre outros.

$\mathrm{Na}$ teoria da geografia, a categoria evento foi internalizada por Milton Santos (2009a) na sua obra "A natureza do espaço", o que foi possibilitado pela definição do espaço como "conjunto indissociável de sistemas de objetos e sistemas de ações". A noção de evento ganha centralidade tal nessa definição do conceito que o próprio autor afirma que essa internalização foi certamente sua contribuição mais importante à teoria geográfica (Santos, 1999). Todavia, poucas foram, desde então, as pesquisas que operaram diretamente com essa categoria, entre as quais merecem destaque as contribuições aportadas por Gallo (2011), Cataia (2013), Ribeiro (2015) e F. Silva (2015).

$\mathrm{Na}$ compreensão que temos da categoria evento a partir de autores como Whitehead (1994), Bachelard (1994, 2007), Santos (2009a), Elias (1998) e M. Silveira (2013), o evento é, em poucas palavras, uma fatia de espaço-tempo. "[...] tempo e [...] espaço [...] constituem abstrações a partir de elementos mais concretos da natureza, isto é, dos eventos" (Whitehead, 1994, p. 41). Isso significa que, na verdade, o espaço tem duração, na forma de períodos, e o tempo tem extensão, dada pela abrangência da ação.

Em nossa opinião, Santos (2009a) traz três contribuições importantes que nos permitem tratar o PBF e, de maneira ampla, uma política pública, como evento: (1) ao diferenciar os eventos naturais dos eventos sociais, afirma que estes últimos têm meios específicos de prolongarem-se, destacando-se aqui a ideia de duração organizacional, referida principalmente aos acontecimentos planejados; (2) o Estado tem uma especificidade importante, pois é o único que "[...] age sobre a totalidade das pessoas, das empresas, das instituições e do território" (Santos, 2009a, p. 152); (3) Um conjunto de eventos pode ser considerado também "[...] um evento, do qual os eventos singulares que o formam são elementos" (Santos, 2009a, p. 154), ou seja as várias ações que demandam o funcionamento de uma política pública podem ser compreendidas como um evento.

Podemos avançar nas proposições de Milton Santos afirmando que, se o objetivo for compreendermos as implicações socioespaciais das ações do Estado, uma possibilidade 
seria tratar os eventos como verdadeiros elos entre o político-institucional e o território usado de uma nação. $\mathrm{Na}$ verdade, tratar-se-ia de problematizar a dialética entre duas instâncias da realidade a partir da empiricização do tempo, isto é, o político-institucional se ligaria ao território porque, a partir do impulso da totalidade em movimento, algo acontece a partir dos meios específicos com os quais o Estado age. $O$ esforço seria direcionado a compreender, ao mesmo tempo, a atualidade do Estado e do território.

O PBF foi criado em outubro de 2003 por meio da Medida Provisória n. 132 (Brasil, 2003), convertida na Lei n. 10.836, de 9 de janeiro de 2004 (Brasil, 2004a), e regulamentado pelo Decreto n. 5.209 de 17 de setembro de 2004 (Brasil, 2004b). A citada medida provisória afirma no seu parágrafo único que esse "programa [...] tem por finalidade a unificação dos procedimentos de gestão e execução das ações de transferência de renda do governo federal [...]", isto é, dos três programas criados nos dois últimos anos do governo Fernando Henrique Cardoso (Bolsa Escola, Bolsa Alimentação e Auxílio Gás) e do Cartão Alimentação criado no início do governo Lula. Segundo Cotta (2009) e Tomazini (2010), o PBF é a síntese contraditória de modos variados de perceber a pobreza, que se manifesta tanto na continuidade de dimensões importantes de programas anteriores - como é o caso das condicionalidades - como na disputa pela inserção de novas dimensões pouco contempladas - caso da proposta de renda básica de cidadania do senador Eduardo Suplicy, já aprovada pela Lei n. 10.835 (Brasil, 2004c), mas ainda não implantada. Verificamos assim a força dos mecanismos que acomodaram as políticas de transferência de renda no território brasileiro durante a década de 1990.

Porém, uma grande novidade do PBF está na estruturação legal-institucional da política, o que prolonga sua duração organizacional. O Decreto n. 5.209 (Brasil, 2004b), que regulamentou o PBF, estabelece no seu artigo primeiro que "o Programa Bolsa Família [...] será regido por este Decreto e pelas disposições complementares que venham a ser estabelecidas pelo Ministério do Desenvolvimento Social e Combate à Fome" (grifos nossos). Antes, o Programa funcionava por meio de uma Secretaria Executiva vinculada diretamente à Presidência da República. Caberia a esse Ministério recémcriado, em particular à Secretaria Nacional de Renda de Cidadania (Senarc), a gestão do PBF, realizando atividades como: gestão dos benefícios do programa, supervisão do cumprimento das condicionalidades, acompanhamento e fiscalização do programa, promoção de uma gestão compartilhada com os municípios e coordenação e gestão do Cadastro Único para programas sociais do governo federal, o Cad. Único.

Ademais, duração organizacional eárea de incidência do evento são dois elementos que guardam relações de dependência. Destaca-se, por exemplo, a Portaria GM-MDS n. 246 de 2005 (Brasil, 2005), que aprova os instrumentos necessários à formalização da adesão dos municípios ao Programa. Este foi o instrumento que garantiu a institucionalização do PBF em todos os municípios brasileiros. Antes dessa Portaria as relações dos municípios eram maiores com a Caixa Econômica Federal (Caixa) do que com o próprio Ministério gestor do PBF, o MDS. Portanto, podemos dizer com certa segurança que o PBF é um 
evento de escala nacional. Primeiro por conta da sua abrangência, isto é, está presente em todo o território brasileiro, e segundo por que na análise do processo que culminou na sua constituição "[...] é insuficiente considerar, apenas, o universal [...]" (Goblot, ${ }^{3} 1967$, p. 10 apud Santos, 2009a, p. 125).

Portanto várias ações, instituições, normas e objetos, atuando em sistema, estão envolvidos no funcionamento do PBF. É a sistematicidade que confere unidade ao evento. Esse sistema envolve diretamente o MDS, responsável pela coordenação da política; o Ministério da Educação (MEC), responsável pelo acompanhamento da frequência escolar; o Ministério da Saúde - MS, responsável pelo acompanhamento da condicionalidade de saúde; os municípios, responsáveis pela execução ${ }^{4}$ da política, e os Estados, corresponsáveis nessa execução; e a Caixa, agente operador/pagador do Programa.

\section{A escala de realização do evento: Programa Bolsa Família e circuitos da economia urbana no interior de Alagoas}

Até aqui dedicamos boa parte do artigo a discutir as escalas de origem do PBF. Todavia, a compreensão de um evento só se perfaz quando este é analisado também a partir de sua escala de realização. Aí o evento é solidário com outros originados em diferentes escalas (global, nacional, regional e local), gerando uma combinação diferente da soma das partes. Trata-se do exercício de identificar como "cada evento estendese por sobre outros eventos e por sobre cada evento estendem-se outros eventos" (Whitehead, 1994, p. 72).

Iremos privilegiar a dimensão das transferências na análise a seguir, estando cientes de que é possível fazer um esforço similar a partir de outras perspectivas. Nesse sentido, ressalta-se a novidade do PBF no que diz respeito à ampliação dos valores transferidos para as famílias e à criação de novos benefícios. O PBF universalizou a elegibilidade às políticas de transferência dentro de certo critério de renda. Estabeleceu o benefício básico, para todas as famílias com renda per capita de até $R \$ 50,00$ mensais, e o benefício variável destinado às famílias com renda per capita de até $R \$ 100,00$, mas que tivessem em sua composição familiar crianças e adolescentes. Com essa medida, segundo Rocha (2013, p. 101), "[...] a clientela-alvo do programa praticamente dobrou" em comparação com os programas anteriores.

A Tabela 1 mostra que desde 2003 vários outros benefícios têm sido criados e, os seus valores, reajustados. Sem dúvida alguma, destaca-se a criação do Benefício para Superação da Extrema Pobreza (BSP) em 2012, no âmbito do Programa Brasil Sem Miséria (PBSM), pois trata-se de um benefício que complementa a renda daquelas

3 GOBLOT, J. J. Pour une approche théorique des facts de civilisation. La Prensée 1333, 134, 136 juin 1967, aoüt, 1967, déc. 1967.

4 Aqui, estamos adotando a perspectiva de Marta Arretche (2004) sobre as relações federativas no âmbito das políticas públicas brasileiras. 
famílias que mesmo recebendo os outros benefícios do PBF não ultrapassavam a linha da pobreza extrema ( $R \$ 70,00$ em 2012). Observamos também que a criação do BSP é um marco importante na trajetória do PBF porque até então os maiores aumentos nos valores das transferências vinham se dando nos benefícios variáveis, isto é, com foco nas condicionalidades de saúde e educação, como se nota entre os anos de 2009 e 2011.

\section{Tabela 1}

\section{Evolução dos valores e benefícios do Programa Bolsa Família (2003-2015)}

\begin{tabular}{|c|c|c|c|c|c|c|c|c|c|}
\hline \multicolumn{10}{|c|}{ Valores nominais e reais em meses de repercussão na folha de pagamento (R\$) } \\
\hline $\begin{array}{c}\text { tipo de } \\
\text { benefício }\end{array}$ & $\begin{array}{c}2003 \\
\text { out. }\end{array}$ & $\begin{array}{c}2007 \\
\text { ago. 1 }\end{array}$ & $\begin{array}{c}\text { BVJ/2008 } \\
\text { mar. 2 }\end{array}$ & $\begin{array}{c}2008 \\
\text { jul. 3 }\end{array}$ & $\begin{array}{c}2009 \\
\text { set. 4 }\end{array}$ & $\begin{array}{c}2011 \\
\text { abr. 5 }\end{array}$ & $\begin{array}{c}2011 \\
\text { set. 6 }\end{array}$ & $\begin{array}{c}\text { criação } \\
\text { do BSP } \\
\text { em 2012 } \\
\text { jun. 7 }\end{array}$ & $\begin{array}{c}2014 \\
\text { jun. 8 }\end{array}$ \\
\hline básico & 50 & 58 & 58 & 62 & 68 & 70 & 70 & & 77 \\
\hline variável & 15 & 18 & 18 & 20 & 22 & 32 & 32 & & 35 \\
\hline jovens & & & 30 & 30 & 33 & 38 & 38 & & 42 \\
\hline BSP & 95 & 112 & 172,00 & 182 & 200 & 242 & 306 & $\begin{array}{c}\text { sem } \\
\text { limite }\end{array}$ & \begin{tabular}{c} 
sem limite \\
\hline máximo
\end{tabular} \\
\hline
\end{tabular}

fonte: Ministério do Desenvolvimento Social e Combate à Fome (Brasil, [s.d]).

organização: Fernando Silva (2015).

1 - Alteração nos benefícios pelo Decreto n. 6.157 de 16 jul. 2007 (Brasil, 2007a).

2 - Benefício Variável Vinculado ao Adolescente (16 e 17 anos) instituído pela Medida Provisória n. 411, de 28 dez. 2007 (Brasil, 2007b), convertida na Lei n. 11.692, de 10 jun. 2008 (Brasil, 2008a).

3 - Alteração nos benefícios pelo Decreto n. 6.491 de 26 jun. 2008 (Brasil, 2008b).

4 - Alteração nos benefícios pelo Decreto n. 6.917 de 30 jul. 2009 (Brasil, 2009).

5 - Alteração nos benefícios pelo Decreto n. 7.447 de 1 mar. 2011 (Brasil, 2011).

6 - Expansão do limite de beneficiários de até 15 anos de 3 para 5 por domicílio e concessão de um benefício variável para gestantes e nutrizes.

7 - Benefício para Superação da Extrema Pobreza na primeira infância instituído pelo Decreto n. 7.758 de 15 jun. 2012 (Brasil, 2012). Consiste na complementação da renda domiciliar per capita até a linha de extrema pobreza para aquelas famílias que não alcançavam esse patamar mesmo recebendo os outros benefícios. Foi aplicado primeiro nos domicílios com criança de 0 a 6 anos, em seguida ampliou-se para a faixa etária de até 15 anos e, no início de 2013, alcançou todos os beneficiários.

8 - Alteração nos benefícios pelo Decreto n. 8.232 de 30 abr. 2014 (Brasil, 2014).

Desse modo, os valores totais das transferências têm aumentado de maneira expressiva. A Tabela 2 traz a evolução dos repasses no Brasil no período de 2004 a 2015. Os valores passaram 
de pouco mais de $R \$ 3,7$ bilhões para $R \$ 25,3$ bilhões, um aumento de mais de $660 \%$. No início do Programa, o aumento de valor das transferências se relaciona principalmente à incorporação de novas famílias, como se pode ver na segunda coluna da Tabela 2; a partir de 2009, o aumento diz respeito sobretudo à criação e ajustes de novos benefícios.

\section{Tabela 2}

Brasil: evolução do número de famílias beneficiárias e dos valores repassados pelo Programa Bolsa Família (2004-2015)

\begin{tabular}{|c|c|c|}
\hline ano & $\mathbf{n}^{\mathbf{0}}$ de familias beneficiárias & valor total repassado em R\$ \\
\hline 2004 & 6.571 .839 & $3.791 .785 .038,00$ \\
\hline 2005 & 8.700 .445 & $5.691 .667 .041,00$ \\
\hline 2006 & 10.965 .810 & $7.524 .661 .322,00$ \\
\hline 2007 & 11.043 .076 & $8.965 .499 .608,00$ \\
\hline 2008 & 10.557 .996 & $10.606 .500 .193,00$ \\
\hline 2009 & 12.370 .915 & $12.454 .702 .501,00$ \\
\hline 2010 & 12.778 .220 & $14.372 .702 .865,00$ \\
\hline 2011 & 13.352 .306 & $17.360 .387 .445,00$ \\
\hline 2012 & 13.902 .155 & $21.156 .744 .695,00$ \\
\hline 2013 & 14.086 .199 & $24.890 .107 .091,00$ \\
\hline 2014 & 14.003 .441 & $27.185 .773 .070,00$ \\
\hline 2015 & 13.782 .217 & $25.379 .505 .412,00$ \\
\hline
\end{tabular}

fonte: Ministério do Desenvolvimento Social e Combate à Fome (Brasil, [s.d]). organização: Fernando Silva (2016).

A distribuição dos beneficiários e das transferências no território brasileiro é bastante desigual, com a região Nordeste concentrando cerca de metade da população beneficiária e dos recursos transferidos. Quatro estados nordestinos (Maranhão, Piauí, Alagoas e Paraíba, nesta ordem) e dois do Norte (Acre e Pará, nesta ordem) são aqueles com maior parcela de suas populações recebendo benefícios do Programa, conforme o Mapa 1. 


\section{Mapa 1}

Brasil: porcentagem da população beneficiária do Programa Bolsa Família (2015) entre a população total estimada para 2015 por unidade da federação

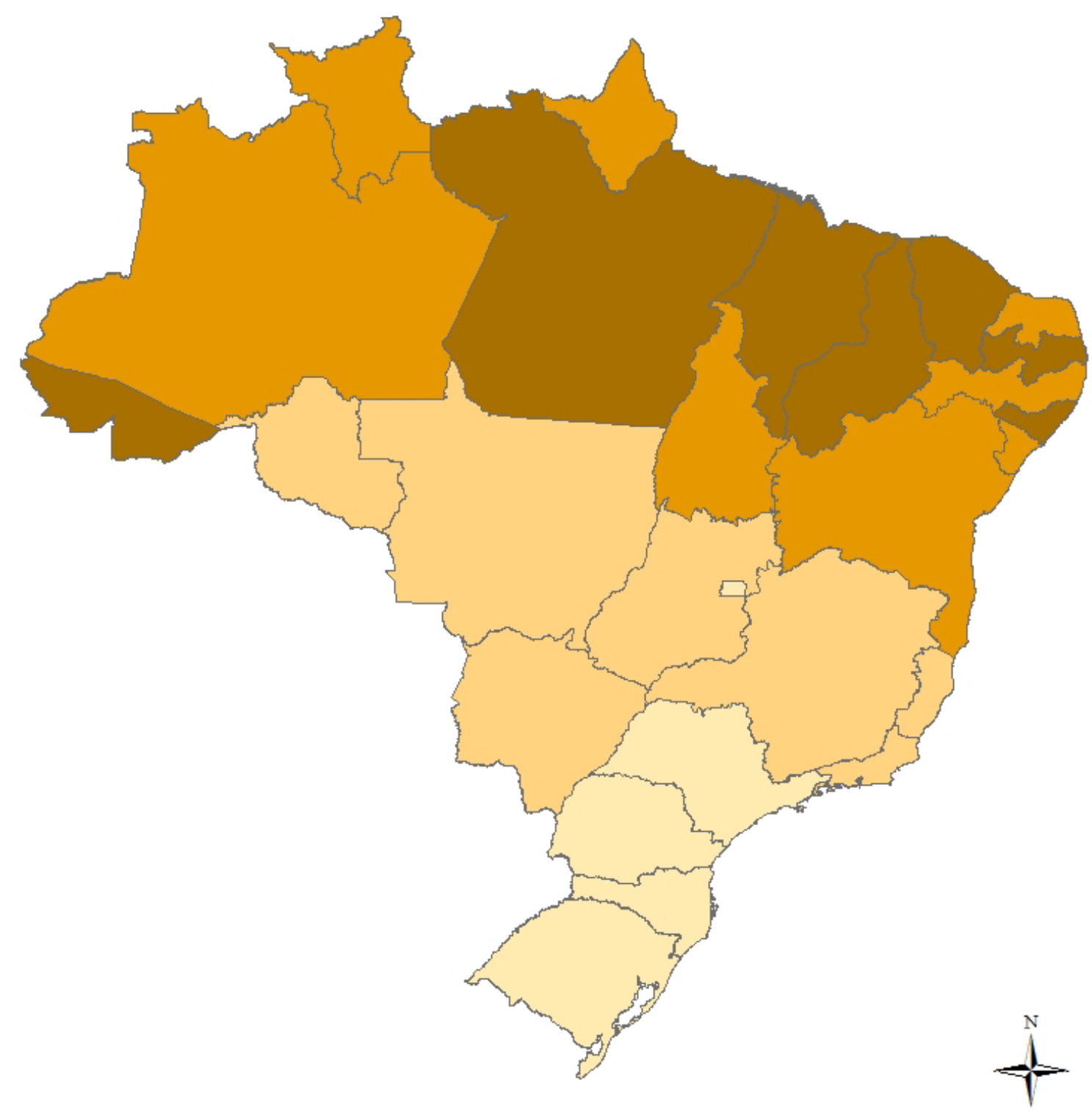

\begin{tabular}{|l|}
\hline Legenda \\
Unidades da Federação \\
$\%$ da População Beneficiánia do Bolsa Família \\
\begin{tabular}{|l}
$\square, 920-12,410$ \\
$12,411-21,060$ \\
$21,061-38,830$ \\
$38,831-48,450$
\end{tabular} \\
\hline
\end{tabular}

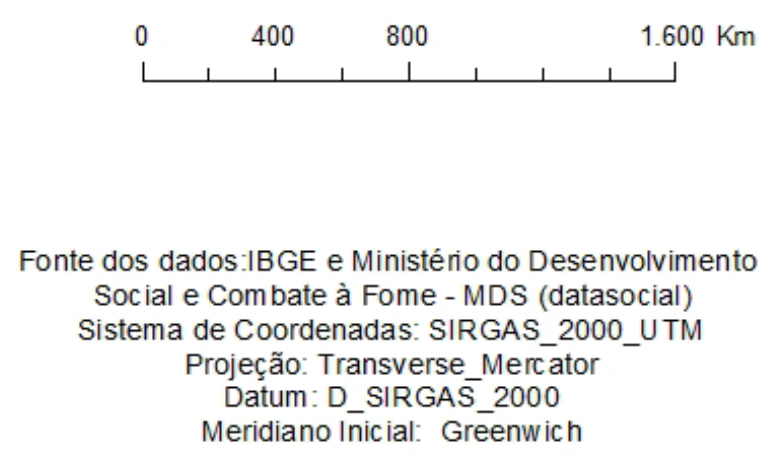

elaboração: Hugo Guilherme C. de Abreu.

organização: Fernando Silva (2016). 
Como as famílias beneficiárias estão entre as populações mais pobres do Brasil, nas diversas regiões o dinheiro do benefício é gasto com bens básicos como: alimentação, material escolar, roupas etc. $O$ Quadro 2 mostra que a alimentação se destaca como gasto principal.

\section{Quadro 2}

Principais gastos com o dinheiro do Programa Bolsa Família em 2007

\begin{tabular}{|c|c|}
\hline destino do dinheiro & \% de beneficiários que destina o dinheiro para esse fim ${ }^{\mathbf{1}}$ \\
\hline alimentação & $87 \%^{2}$ \\
\hline material escolar & $46 \%^{3}$ \\
\hline vestuário & $37 \%$ \\
\hline remédios & $22 \%$ \\
\hline gás & $10 \%$ \\
\hline luz & $6 \%$ \\
\hline tratamento médico & $2 \%$ \\
\hline água & $1 \%$ \\
\hline outras opções & menos de $1 \%$ \\
\hline
\end{tabular}

fonte: Ibase (2008).

organização: Fernando Silva (2016).

1: Para a pesquisa foram entrevistados 5 mil titulares de cartão do PBF em 229 municípios das cinco regiões brasileiras;

2: A maior porcentagem é do Nordeste (91\%) e a menor do Sul (73\%);

3: A maior porcentagem é do Norte $(63,5 \%)$ e a menor do Nordeste (40\%)

Defendemos que outro aspecto muito importante para compreendermos o PBF a partir de sua escala de realização é considerar a forma de pagamento dos benefícios, herança do Programa Bolsa Escola (Brasil, 2001a). A Medida Provisória de criação do PBF (Brasil, 2003) estabeleceu, no seu artigo 10: "Fica atribuída à Caixa Econômica Federal a função de agente operador do Programa Bolsa Família, mediante remuneração e condições a serem pactuadas com o governo federal, obedecidas as formalidades legais". Portanto, o dinheiro chegaria às populações pelo cartão magnético, por meio de um banco público. Segundo Santos (2008), os bancos podem ser analisados como agentes do circuito superior da economia urbana. Portanto, é considerando a dinâmica 
das populações beneficiárias, o consumo e o papel dos fixos bancários na efetivação das transferências que propomos pensar as novas dinâmicas territoriais decorrentes do PBF na escala em que este se realiza a partir da teoria dos dois circuitos da economia urbana (Santos, 2008).

Nos termos dessa teoria, as cidades dos países periféricos podem ser analisadas a partir da distinção entre as atividades econômicas que ocupam e dinamizam os espaços urbanos. Essa distinção é feita a partir de três variáveis dinâmicas: capitais, técnicas e organização. Grandes empresas industriais e de serviços, fundos de pensão, grandes bancos etc., compõem o circuito superior da economia urbana, pois atuam com grandes quantidades de capital, sistemas técnicos que se renovam constantemente e métodos organizacionais rígidos; já o circuito inferior da economia é composto por pequenas indústrias, comércios e serviços, cujo capital é restrito e as técnicas e a organização são mais flexíveis. As populações também são elementos constituintes dos circuitos da economia urbana: simplificando, aquelas que auferem altos rendimentos inserem-se no circuito superior; já as populações de baixos rendimentos, como é caso de todas as famílias beneficiárias do PBF, compõem o circuito inferior.

Como vimos no Mapa 1, o estado de Alagoas apresenta situações significativas para problematizar as novas dinâmicas territoriais decorrentes do PBF porque está entre aqueles com maiores parcelas de sua população inseridas no Programa. Desde 2013, temos feito trabalhos de campo em algumas cidades do interior desse estado, lançando mão de levantamento de dados secundários, aplicação de questionários e entrevistas com os diversos agentes implicados pela política, mas especialmente com beneficiários do PBF e trabalhadores do circuito inferior da economia urbana. A reflexão que desenvolvemos a seguir está baseada sobretudo nesses trabalhos de campo.

Ente federativo brasileiro com uma economia assentada historicamente na plantação de cana-de-açúcar, Alagoas conheceu transformações importantes no uso do seu território a partir da desregulamentação do setor sucroalcooleiro na década de 1990, levada a efeito pela extinção do Instituto do Açúcar e do Álcool, em 1991. Processos tais como expansão da plantação de cana para terras de cultivos alimentares e mudanças nas relações de trabalho (sazonalização do trabalho, fim do sistema de moradas etc.), que já vinham ocorrendo desde a década de 1970, somam-se ao aumento do desemprego pela falência de pequenas usinas e pelo acirramento da competitividade entre as maiores.

Além da aceleração da urbanização em Maceió, cidade que concentra desde 1970 cerca de $40 \%$ da população urbana alagoana, pequenas e médias cidades, especialmente do litoral e da Zona da Mata, vivenciaram um processo significativo de urbanização da pobreza. Alagoas chega ao final do século XX como um dos estados mais pobres da federação: a segunda menor renda per capita $(R \$ 278,72)$ do Nordeste e a segunda maior porcentagem de pessoas consideradas pobres $(62,24 \%)$, isto é, vivendo com menos de meio salário mínimo. E a maior parte dessas populações vive agora nas cidades (IBGE, 1970, 1980, 1991, 2000, 2010).

O que temos visto é que o PBF tornou mais complexas as formas de reprodução 
da pobreza nas cidades alagoanas. Embora a pobreza se manifeste nessas cidades, multiplica seus nexos com agentes e processos de diversas escalas geográficas. Nesse sentido, destacamos o caso do gasto decorrente da exigência da condicionalidade de educação. Podemos constatar que as cidades que concentram o maior número de crianças e adolescentes acompanhadas na condicionalidade de educação, como mostra o Mapa 2, sediam o maior número de micro e pequenas empresas de comércio varejista de papelaria, de acordo com o Mapa 3. Essa concentração também tem a ver com o poder de organização dos espaços urbanos que passam a ter as casas lotéricas em cidades em que mais da metade da população é beneficiária do PBF. Ainda que praticamente todas as cidades tenham pelo menos uma casa lotérica, são frequentes nas pequenas cidades os casos em que falta dinheiro para pagamento ou a conexão com o sistema da Caixa para de funcionar várias vezes durante o dia. Como as populações beneficiárias precisam urgentemente do benefício, geralmente tomam emprestado dinheiro para passagem e vão receber nas cidades maiores, realizando aí também os gastos com material escolar.

\section{Mapa 2}

Alagoas: número de crianças e adolescentes acompanhados nas condicionalidades de educação do Programa Bolsa Família por cidade em maio de 2015

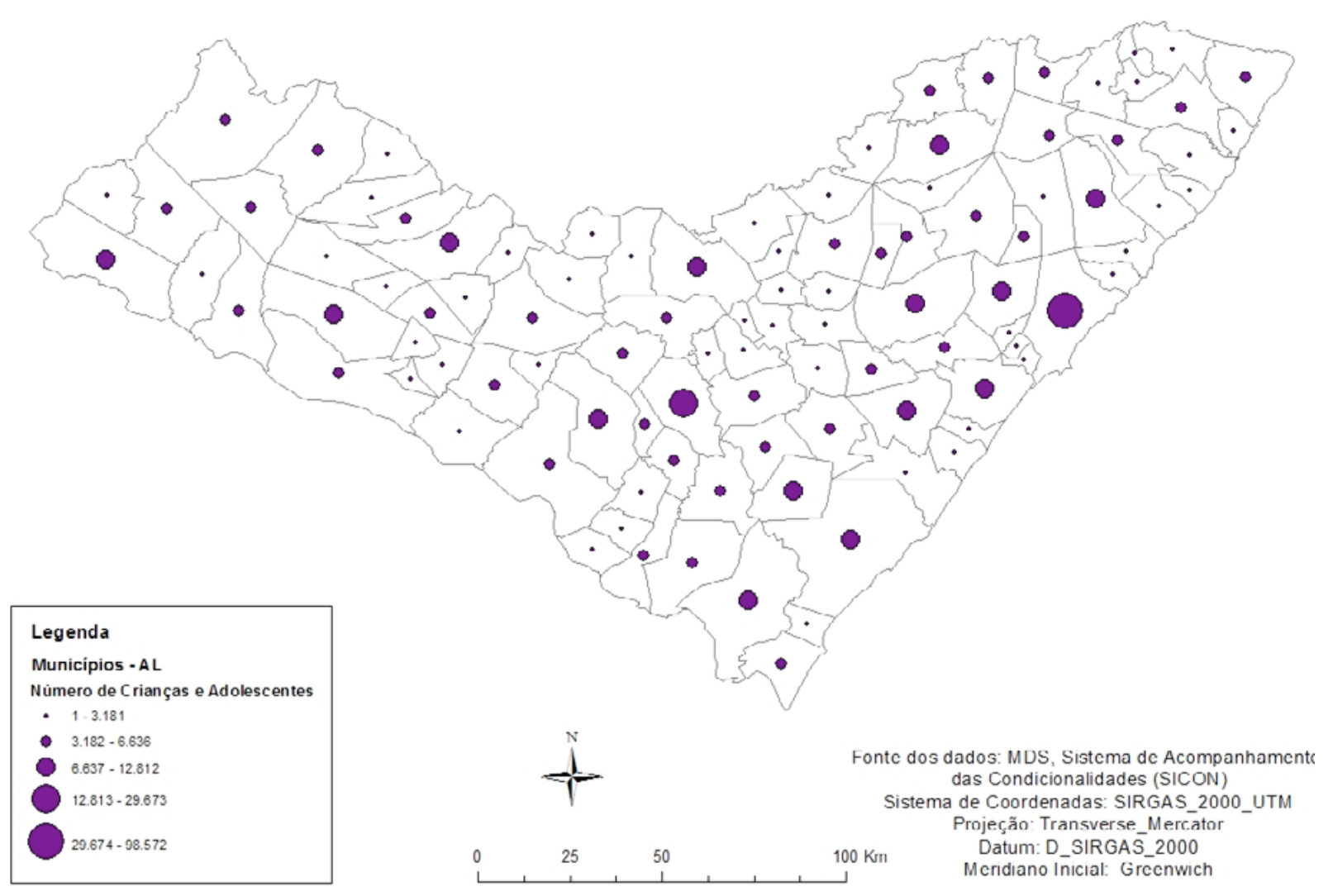

elaboração: Hugo Guilherme C. de Abreu.

organização: Fernando Silva (2016). 


\section{Mapa 3}

Alagoas: número de micro e pequenas empresas de comércio varejista de artigos de papelaria por cidade em 2015

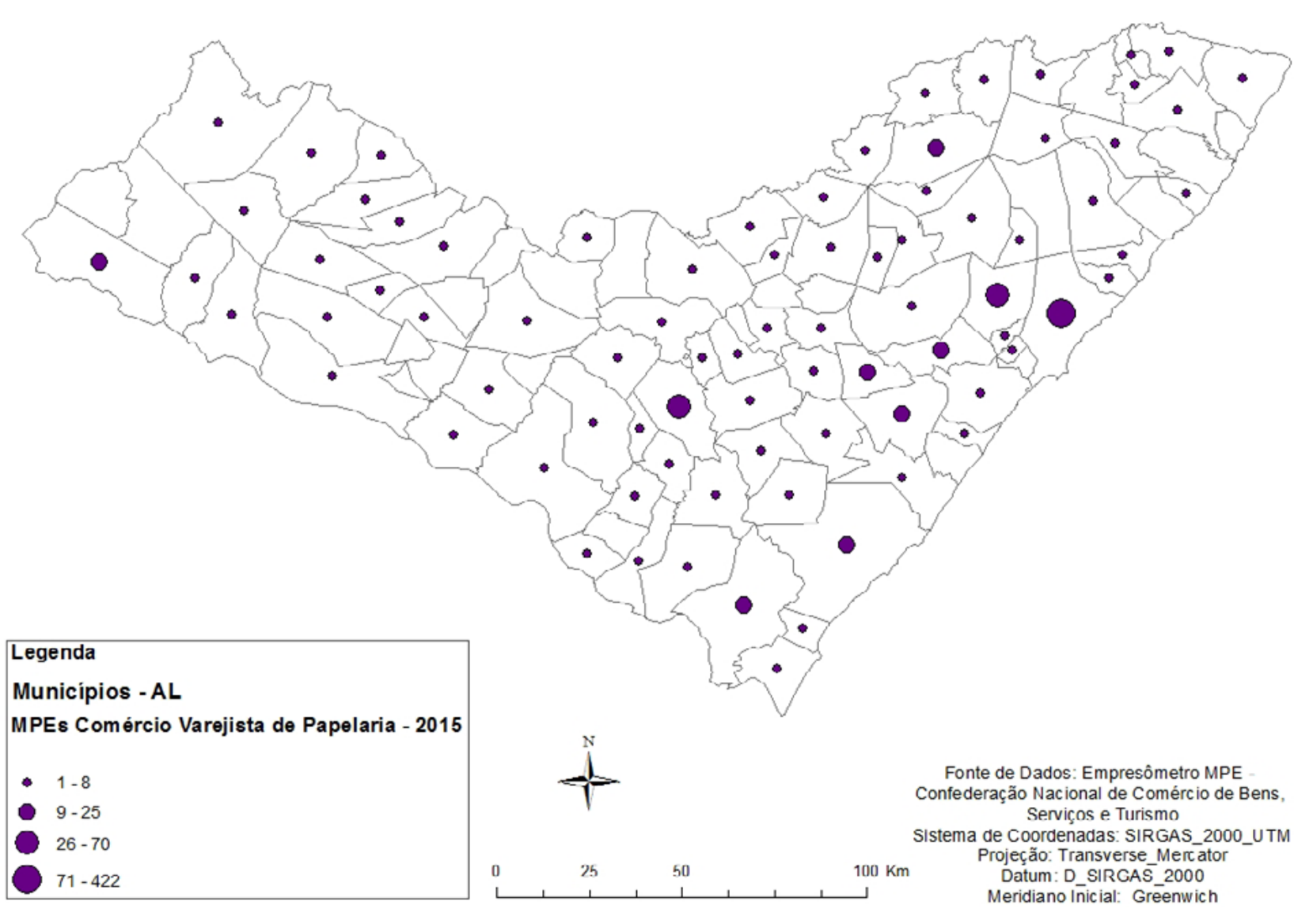

elaboração: Hugo Guilherme C. de Abreu.

organização: Fernando Silva (2016).

Desse modo, a exigência de frequência escolar para crianças e adolescentes beneficiários do PBF parece alimentar um conjunto de atividades do circuito inferior da economia urbana, no seio das quais vamos identificar novas relações de cooperação e, sobretudo, de subordinação entre dois circuitos da economia urbana. Essas atividades são essencialmente: produção e comercialização de fardamento escolar, lanches, serviços de xerox, mas principalmente comércio de produtos de papelaria. Neste último, por exemplo, as mercadorias que os trabalhadores do circuito inferior da economia urbana comercializam provêm de indústrias do circuito superior localizadas sobretudo no Sudeste do país, e chegam às pequenas e médias cidades alagoanas pelos distribuidores também do circuito superior. Várias pesquisas destacam aspectos positivos nas condicionalidades do PBF, mas, de nossa parte, parece correto afirmar também que, ao direcionar o consumo, a exigência de frequência escolar limita as possibilidades de articulação horizontal (Silveira, M., 2014) do circuito inferior da economia urbana, isto é, 
atua contrariamente à articulação da economia do lugar e da região.

Completa esse quadro o grande senso de responsabilidade que as mães têm para com o futuro dos filhos, influenciado, em parte, pelo pensamento dominante de que o foco das transferências de renda no Brasil é o futuro das crianças. Em conversas com essas mães em nossos trabalhos de campo muitas afirmaram que as despesas relacionadas à escola dos filhos são mais importantes que a própria alimentação de casa. Se esse pensamento é central para a reprodução de algumas atividades do circuito inferior da economia urbana, a equação não deixa de ser perversa: deixa-se de comprar um quilo de feijão, por exemplo, para que o filho copie um texto da internet na lan house e entregue na escola.

\section{Considerações finais}

Parece sensato dizer que analisar as políticas de transferências de renda a partir das dinâmicas socioespaciais constitui um caminho muito proveitoso para evidenciar dimensões dessas políticas que ainda não foram captadas pelos diversos estudos feitos principalmente no âmbito da ciência política, sociologia e economia.

Pensamos que os argumentos apresentados neste artigo permitem extrair quatro considerações principais. Primeiro, a dinâmica do território brasileiro revela nitidamente a convergência entre o período atual, da pobreza estrutural globalizada, e a adoção das políticas de transferência de renda. Sem desconsiderar todos os avanços trazidos por essas políticas a partir do governo Lula, diríamos que os elementos fundantes do PBF encontram-se nos mecanismos propulsores da globalização e as concepções reducionistas de pobreza que estes instalam. Segundo, a categoria evento tem potencialidade ainda inexplorada na geografia e que podem contribuir para essa disciplina aprofundar-se no debate sobre as políticas públicas. Terceiro, a teoria dos dois circuitos da economia urbana, embora não seja o único caminho possível, indica possibilidades reais de problematizar várias dimensões do PBF (transferências, condicionalidades, o papel da Caixa, as dinâmicas locais das economias etc.), vistas nas suas relações recíprocas. Por fim, o PBF torna mais complexa e institucionalizada a reprodução da pobreza, isto é, os pobres continuam em seus lugares, mas a pobreza aumenta os nexos com diferentes escalas geográficas e se reproduz cada vez mais por meio de políticas e instituições do nosso país.

\section{Referências}

ARRETCHE, M. Federalismo e políticas sociais no Brasil: problemas de coordenação e autonomia. São Paulo em Perspectiva, v. 18, n. 2, p. 17-26, 2004.

BACHA, E.; UNGER, R. M. Um projeto de democracia para o Brasil: participação, salário e voto. Rio de janeiro: Paz e Terra, 1978.

BACHELARD, G. A intuição do instante. Trad. Antonio de Padua Danesi. Campinas, SP: Verus, 2007. 
A dialética da duração. Trad. Marcelo Coelho. 2. ed. São Paulo: Ática, 1994.

BRASIL. Ministério do Desenvolvimento Social e Combate à Fome (MDS). Ferramenta DataSocial, [s.d]. Disponível em: http://aplicacoes.mds.gov.br/sagi/simulacao/layout/teste/ miv novo.php. Acesso em: 11 abr. 2017.

BRASIL. Decreto n. 8.232, de 30 de abril de 2014. Altera o Decreto n. 5.209, de 17 de setembro de 2004, que regulamenta o Programa Bolsa Família, e o Decreto n. 7.492, de 2 de junho de 2011, que institui o Plano Brasil Sem Miséria. Diário Oficial da União, Casa Civil, Brasilia, DF, 2014.

BRASIL. Decreto n. 7.758, de 15 de junho de 2012. Altera o Decreto n. 5.209, de 17 de setembro de 2004, que regulamenta a Lei n. 10.836, de 9 de janeiro de 2004, que cria o Programa Bolsa Família. Diário Oficial da União, Casa Civil, Brasília, DF, 2012.

BRASIL. Decreto n. 7.447, de 1 mar. de 2011. Dá nova redação ao art. 19 do Decreto n. 5.209, de 17 de setembro de 2004, que regulamenta a Lei n. 10.836, de 9 de janeiro de 2004, que cria o Programa Bolsa Família. Diário Oficial da União, Casa Civil, Brasília, DF, 2011.

BRASIL. Decreto n. 6.917, de 30 de julho de 2009. Altera os arts. 18, 19 e 28 do Decreto n. 5.209, de 17 de setembro de 2004, que regulamenta a Lei n. 10.836, de 9 de janeiro de 2004, que cria o Programa Bolsa Família. Diário Oficial da União, Casa Civil, Brasília, DF, 2009.

BRASIL. Lei n. 11.692, de 10 de junho de 2008. Dispõe sobre o Programa Nacional de Inclusão de Jovens - Projovem, instituído pela Lei n. 11.129, de 30 de junho de 2005; altera a Lei n. 10.836, de 9 de janeiro de 2004; revoga dispositivos das Leis n. 9.608, de 18 de fevereiro de 1998, 10.748, de 22 de outubro de 2003, 10.940, de 27 de agosto de 2004, 11.129, de 30 de junho de 2005, e 11.180, de 23 de setembro de 2005; e dá outras providências. Diário Oficial da União, Casa Civil, Brasília, DF, 2008a.

BRASIL. Decreto n. 6.491, de 26 de junho de 2008. Dá nova redação ao art. 19 do Decreto n. 5.209, de 17 de setembro de 2004, que regulamenta a Lei n. 10.836, de 9 de janeiro de 2004, que cria o Programa Bolsa Família. Diário Oficial da União, Casa Civil, Brasília, DF, 2008b.

BRASIL. Decreto n. 6.157, de 16 de julho de 2007. Dá nova redação ao art. 19 do Decreto n. 5.209, de 17 de setembro de 2004, que regulamenta a Lei n. 10.836, de 9 de janeiro de 2004, que cria o Programa Bolsa Família. Diário Oficial da União, Casa Civil, Brasília, DF, 2007a. p. 1. 
BRASIL. Medida Provisória n. 411, de 28 de dezembro de 2007. Dispõe sobre o Programa Nacional de Inclusão de Jovens - ProJovem, instituído pela Lei n. 11.129, de 30 de junho de 2005, altera a Lei n. 10.836, de 9 de janeiro de 2004, e dá outras providências. Diário Oficial da União, Casa Civil, Brasília, DF, 2007b. Seção Extra, p. 6.

BRASIL. Ministério do Desenvolvimento Social e Combate à Fome. Portaria n. 246, de 20 de maio de 2005. Aprova os instrumentos necessários à formalização da adesão dos municípios ao Programa Bolsa-Família, à designação dos gestores municipais do Programa e à informação sobre sua instância local de controle social, e define o procedimento de adesão dos entes locais ao referido Programa. Diário Oficial da União, Brasília, DF, 2005.

BRASIL. Lei n. 10.836, de 2004. Cria o Programa Bolsa Familia e dá outras providências. Diário Oficial da União, Casa Civil, Brasília, DF, 2004a.

BRASIL. Decreto n. 5.209, de 17 de setembro de 2004. Regulamenta a Lei n. 10.836, de 9 de janeiro de 2004, que cria o Programa Bolsa Família, e dá outras providências. Diário Oficial da União, Casa Civil, Brasília, DF, 2004 b.

BRASIL. Lei n. 10.835, de 2004. Institui a renda básica de cidadania e dá outras providências. Diário Oficial da União, Casa Civil, Brasilia, DF, 2004c.

BRASIL. Medida Provisória n. 132, de 20 de outubro de 2003. Cria o Programa Bolsa Família e dá outras providências. Diário Oficial da União, Casa Civil, Brasília, DF, 21 out. 2003.

BRASIL. Congresso. Senado. Projeto de Lei n. 266, 4 de dezembro de 2001, de E. M. Suplicy. Institui a Renda Básica Incondicional ou a Renda de Cidadania e dá outras providências. Brasília: Senado Federal, 2001a.

BRASIL. Medida Provisória n. 2.140, de 13 de fevereiro de 2001. Cria o Programa Nacional de Renda Mínima vinculada à educação - "Bolsa Escola", e dá outras providências. Diário Oficial da União, Casa Civil, Brasília, DF, 14 fev. 2001 b.

BRASIL. Congresso. Senado. Proposta de Emenda à Constituição n. 67, de 10 de agosto de 1999, de A. C. Magalhães. Altera o Ato das Disposições Constitucionais Transitórias, introduzindo artigos que criam o Fundo de Combate e Erradicação da Pobreza. Brasília: Senado Federal, 1999a.

BRASIL. Congresso. Senado. Projeto de Lei n. 66, de 25 de fevereiro de 1999, de E. M. Suplicy. Institui a linha oficial de pobreza e estabelece que o governo federal deverá definir metas ao longo do tempo de progressiva erradicação da pobreza, diminuição de desigualdades socioeconômicas, e dá outras providencias. Brasília: Senado Federal, 1999b. 
BRASIL. Congresso. Senado. Projeto de Lei n. 80, de 1991, de E. M. Suplicy. Institui o Programa de Garantia de Renda Mínima-PGRM e dá outras providencias. Brasília: Senado Federal, 1991.

CAMARGO, J. M. Os miseráveis. Folha de S.Paulo, São Paulo, 3 mar. 1993.

CATAIA, M. Território e federação: articulações possíveis. Educação e Sociedade, Campinas, SP, v. 34, n. 125, p. 1135-1151, out./dez. 2013.

$\mathrm{COHN}$, A. Cartas ao presidente Lula: Bolsa Família e direitos sociais. Rio de Janeiro: Pensamento Brasileiro, 2012.

COTTA, T. C. S. Visões de proteção social e transferências de renda condicionadas no Brasil e no México. Tese (Doutorado em Ciências Sociais) - Instituto de Ciências Sociais, Universidade de Brasília, Brasília, 2009.

ELIAS, N. Sobre o tempo. Rio de Janeiro: Zahar, 1998.

FONSECA, A. M. M. Família e política de renda mínima. São Paulo: Cortez, 2001.

GALLO, F. Uso do território e federalismo como evento: a difusão regional das infraestruturas analisadas a partir das transferências intergovernamentais voluntárias entre união e municípios. Tese (Doutorado em Geografia) - Instituto de Geociências, Universidade Estadual de Campinas, Campinas, 2011.

GEORGE, P. A ação do homem. São Paulo: Difusão Europeia do Livro, 1968.

ISNARD, H. Espace et Temps en Géographie. Annales de Géographie, n. 525, p. 534-545. 1985.

O espaço geográfico. Coimbra: Livraria Almedina, 1982.

IBASE. INSTITUTO BRASILEIRO DE ANÁLISES SOCIAIS E ECONÔMICAS. Repercussões do Programa Bolsa Família na segurança alimentar e nutricional das famílias beneficiadas. Rio de Janeiro: Ibase, 2008.

IBGE. INSTITUTO BRASILEIRO DE GEOGRAFIA E ESTATÍSTICA. Censo Demográfico 2010. Rio de Janeiro: IBGE, 2010.

IBGE. INSTITUTO BRASILEIRO DE GEOGRAFIA E ESTATÍSTICA. Censo Demográfico 2000. Rio de Janeiro: IBGE, 2000. 
IBGE. INSTITUTO BRASILEIRO DE GEOGRAFIA E ESTATÍSTICA. Censo Demográfico 1991. Rio de Janeiro: IBGE, 1991.

IBGE. INSTITUTO BRASILEIRO DE GEOGRAFIA E ESTATÍSTICA. Censo Demográfico 1980. Rio de Janeiro: IBGE, 1980.

IBGE. INSTITUTO BRASILEIRO DE GEOGRAFIA E ESTATÍSTICA. Censo Demográfico 1970. Rio de Janeiro: IBGE, 1970.

LE GOFF, J. A história deve ser dividida em pedaços?. Trad. Nícia Adan Bonatti. São Paulo: Editora Unesp, 2015.

POLANYI, K. A grande transformação: as origens da nossa época. Trad. Fanny Wrobel. Rio de Janeiro: Campus, 1980.

QUIJANO, A. La economía popular y sus caminos en América Latina. Lima: Mosca Azul, 1998.

RIBEIRO, L. H. L. Território e macrossistema de saúde: os programas de fitoterapia no Sistema Único de Saúde. Tese (Doutorado em Geografia) - Instituto de Geociências, Universidade Estadual de Campinas, Campinas, 2015.

ROCHA, S. Transferências de renda no Brasil: o fim da pobreza?. Rio de Janeiro: Elsevier, 2013.

SANTOS, M. Por uma outra globalização: do pensamento único à consciência universal. Rio de Janeiro: BestBolso, 2011. (Coleção Vira-Vira, 2.)

A natureza do espaço: técnica e tempo, razão e emoção. 4. ed. São Paulo: Edusp, 2009a.

Pensando o espaço do homem. 5. ed. São Paulo: Edusp, 2009b.

O espaço dividido: os dois circuitos da economia urbana dos países subdesenvolvidos. 2. ed. São Paulo: Edusp, 2008.

Por uma geografia nova: da crítica da geografia a uma geografia crítica. 6. ed. São Paulo: Edusp, 2004.

O território e o saber local: algumas categorias de análise. Cadernos IPPUR, Rio de Janeiro, v. XIII, n. 2, p. 16-26, 1999. 
SCHNELL, A. (Org.). Le temps. Paris: Librairie Philosophique J. Vrin, 2007.

SILVA, C. A. Da crise econômica ao neodesenvolvimentismo brasileiro: contribuições para o debate contemporâneo. Revista Terra Livre, v. 28, v. 2, n. 39, p. 95-124, jul./dez 2012.

SILVA, F. A. A dinâmica do território brasileiro no período da globalização: o Programa Bolsa Família como evento. In: ENCONTRO NACIONAL DA ASSOCIAÇÃO NACIONAL DE PÓS-GRADUAÇÃO EM GEOGRAFIA, 11., 2015, Grande Dourados, Anais... Grande Dourados: EdUFGD, 2015. p. 4727-4738.

SILVA, M. O. S. Renda mínima e reestruturação produtiva. São Paulo: Cortez, 1997.

et al. A política social brasileira no século XXI: a prevalência dos programas de transferência de renda. 2. ed. São Paulo: Cortez, 2006.

SILVEIRA, A. M. Redistribuição de Renda. Revista Brasileira de Economia, Rio de Janeiro, v. 29, n. 2, p. 3-15, abr./jun. 1975.

SILVEIRA, M. L. A natureza relacional dos circuitos da economia urbana. In: OLIVEIRA, F. J. G. et al. (Org.). Geografia urbana: ciência e ação política. Rio de Janeiro: Consequência, 2014. p. 155-178.

. Tiempo y espacio en geografía: dilemas y reflexiones. Revista de Geografía Norte Grande, Santiago, v. 54, p. 9-29, mai. 2013.

. Por que há tantas desigualdades sociais no Brasil?. In: ALBUQUERQUE, E. S. (Org.). Que país é esse? Pensando o Brasil contemporâneo. São Paulo: Globo, 2005. p. 141-178.

SPRANDEL, M. A. A pobreza no paraíso tropical: interpretações e discursos sobre o Brasil. Rio de Janeiro: Relume Dumará/Núcleo de Antropologia Política/UFRJ, 2004.

STEIN, R. H. As políticas de transferências de renda na Europa e na América Latina: recentes ou tardias estratégias de proteção social?. Tese (Doutorado em Sociologia) - Instituto de Ciências Sociais, Universidade de Brasília, Brasília, 2005.

SUPLICY, E. M. Renda de cidadania: a saída é pela porta. 7. ed. São Paulo: Cortez, 2013.

TELLES, V. S. Pobreza e cidadania. São Paulo: Editora 34, 2001. 
TOMAZINI, C. G. La construction des politiques de transferts monétaires conditionnels: entre consensus et dissentiments. Une analyse de la lutte contre la pauvreté au Brésil et au Mexique. Dissertação (Mestrado em Ciência Política) Institut des Hautes Études de l'Amérique Latine, Université Paris III, La Sorbonne Nouvelle, Paris, 2010.

UGÁ, V. D. A categoria "pobreza" nas formulações de política social do Banco Mundial. Revista de Sociololgia e Política, Curitiba, n. 23, p. 55-62, nov. 2004.

WHITEHEAD, A. N. O conceito de natureza. São Paulo: Martins Fontes, 1994. 